\title{
COLLABORATING TO MANAGE: A PRIMER FOR THE PUBLIC SECTOR
}

\section{Robert Agranoff \\ Georgetown University Press, 2012, 288 pp., £18.95 (pb), ISBN: 9781589019164}

It is perhaps the most robust public sector change imperative of the last few decades: the growing complexity and interdependence of public policymaking, public problem solving, or - in modern parlance - public value creation. The problems that are most worth tackling yet are also the most intransigent: they transcend jurisdictional and sectoral boundaries and defy standard repertoires and knowledge claims. Yet at the same time our public problem-solving ambitions, whether fuelled by ideology, political expediency, commercial instincts, or commitment to clienteles have hardly diminished in the face of decades of evidence documenting how hard it really is to devise, implement, and steward effective public programmes.

So the battle goes on. What we know is that the government cannot address these intractable problems alone and expect to have a meaningful impact. It needs to work in alignment with parties in the private and non-profit sectors that have critical knowledge, systems, legitimacy, and other problem-solving resources. Moreover, the government itself is a highly differentiated and multi-layered creature, and if its internal processes are not carefully aligned, its organizational silos, intergovernmental tensions, and bureau-political strife will cripple the coherence and effectiveness of its efforts.

All this we have known for some time. But it has only been in the last two decades or so that we have been working through its implications, in both the practice and the study of public administration. In practice, we have seen a global flurry of efforts to coordinate, join up, buy in, and partner across agencies, levels of government, and out to the private and non-profit sectors. In the study of public administration this quest has been observed, interpreted, and indeed actively advocated and enabled by scholars of 'governance', 'network management', and most recently, 'collaborative public management'.

Robert Agranoff has been at the forefront of this development for most of this time. A prize-winning scholar (including the Haldane prize awarded by this journal), he has seen it all, studied it diligently, and has published about it in an impressive series of books and articles. The present book can be seen as an attempt to take all that work, synthesize it, and present it to, as the Preface says, 'professionals who work within and with the new, externally as well as internally geared bureaucracy - the "conductive" public agency and for students who are pursuing or will pursue careers on one or the other side of public programs in the network area'.

By that measure, the book is not a success. This is not because Agranoff does not know his business. On the contrary, he might just know it a bit too well, and has found it difficult to suppress the tendency to take his readers to all the nooks and crannies of his thinking about the subject. As a result, the book is overly dense (note the complexity of the sentence from the Preface, which provides the shape of things to come in the main text), lacks a tight and compelling composition (it is, and still feels like, a collection of papers and lectures), and has the awkward tendency to provide endless multi-item checklists, presumably under the misguided assumption that this is what practitioners want and how they learn. 
This reader, at least, found it all a bit much to take, despite my admiration for the deep and nuanced knowledge on display here. The impersonal writing style does not help either: Agranoff emphasizes on numerous occasions the pivotal role played by the microdynamics of collaboration: the sponsorship of champions, the climate of relations between organizational representatives, trust as a pivotal currency, and so on but manages to do so in a way that remains almost completely silent about the perspectives, dilemmas, and strategies of the individuals and groups in the many detailed cases he presents at various points in the text. For him, much collaboration appears to be about 'tools', structures, and incentives within and across organizations. He does tell us that relational processes like power and social learning are crucial in making or breaking collaborative efforts, but he does not really unpack their dynamics down to the everyday level that most public managers would find most useful.

Perhaps he wants to eschew the other extreme: the strongly person-centred and often somewhat 'heroic' accounts of how the public business is being managed that are offered by proponents of the public value school (e.g. Sanderijn Cels, Jorrit de Jong, and Frans Nauta's Agents of Change (Brookings, 2012) and Mark Moore's Recognizing Public Value (Harvard University Press, 2013)). But it has resulted in a book that is somewhat, well, bloodless. It may be a matter of taste, but I think it is also a matter of pedagogics, how we as academics most effectively narrate and teach public administration. On that count, if I had one textbook to assign in a course on collaborative public management, I would much prefer Barbara Crosby and John Bryson's Leadership for the Common Good (Jossey-Bass, 2008), Russell Linden's Leading across Boundaries (Jossey-Bass, 2010), or, for those tiring of the US-centric orientation of all these texts, Paul Williams' Collaboration in Public Policy and Practice (Policy Press, 2012) and John Alford and Janine O'Flynn's Rethinking Public Service Delivery: Managing with External Providers (Palgrave Macmillan, 2012).

For fellow researchers in this field, the book is still a useful consolidator of the state of the art. It is not especially focused on generating new concepts, hypotheses, or theories. It blurs empirical and prescriptive modes of discourse. But it still has lots of interesting things to say about the shape of post-Fordist bureaucratic organizations (and what design principles are or ought to be underpinning them; pp. 54,67-73, 188-92); the fact that government actors will need to find ways to combine 'authoritative' with 'participatory' modes of engaging with external parties - collaboration is not about abandoning the former in favour of a full dedication to the latter, as doing so would belie the specific nature and mandate of governments (p. 50); the pivotal role played by information, knowledge, and knowledge management in developing and sustaining collaborative relations across institutional actors (pp. 124ff.); and the pivotal roles senior executives (presumably including political office-holders) can - and must - play in nurturing and supporting field-level coordination (pp. 172-73). In short: a rich overview but not the must-use textbook for the next generation of post-bureaucratic, collaboration-focused public managers.

Paul 't Hart

Utrecht University School of Governance and Netherlands School of Public Administration 